\title{
Raízes Sistêmicas da Reestruturação Capitalista Pós-1970: um subsídio geo-histórico
}

Racines systémiques de la restructuration capitaliste postérieure à 1970: une subvention géo-historique

Raíces sistémicas de la reestructuración capitalista posterior a 1970: un subsidio geohistórico

Systemic Roots of Post-1970 Capitalist Restructuring: a geo-historical allowance

\section{Gabriel Souza Alves}

\section{(2) OpenEdition}

Journals

\section{Edição electrónica}

URL: http://journals.openedition.org/espacoeconomia/7799

DOI: 10.4000/espacoeconomia.7799

ISSN: 2317-7837

\section{Editora}

Núcleo de Pesquisa Espaço \& Economia

\section{Refêrencia eletrónica}

Gabriel Souza Alves, «Raízes Sistêmicas da Reestruturação Capitalista Pós-1970: um subsídio geohistórico », Espaço e Economia [Online], 15 | 2019, posto online no dia 30 outubro 2019, consultado o 05 novembro 2019. URL : http://journals.openedition.org/espacoeconomia/7799; DOI : 10.4000/ espacoeconomia.7799

Este documento foi criado de forma automática no dia 5 novembro 2019.

(c) NUPEE 


\title{
Raízes Sistêmicas da Reestruturação Capitalista Pós-1970: um subsídio geo-histórico
}

\author{
Racines systémiques de la restructuration capitaliste postérieure à 1970: une \\ subvention géo-historique \\ Raíces sistémicas de la reestructuración capitalista posterior a 1970: un subsidio \\ geohistórico \\ Systemic Roots of Post-1970 Capitalist Restructuring: a geo-historical allowance
}

Gabriel Souza Alves

\section{Introdução}

1 O percurso desta contribuição tem como ponto de partida algumas reflexões teóricas relevantes para a compreensão da reestruturação contemporânea da economia política. Ao passo em que avançamos sobre algumas indagações e dificuldades de interpretação, devemos recorrer à uma sistematização baseada nas experiências pretéritas do sistema capitalista, na busca por compreender seu comportamento e funcionalidade ao longo de suas trajetórias no espaço-tempo. Seja para analisar o funcionamento do capitalismo nos dias de hoje, seja para dimensionar as heranças que sobreviveram na espacialidade do capitalismo, olhar para o passado - sem negligenciar o presente - é fundamental para compreender como vem se dando as lutas entre o velho e o novo dentro da reestruturação econômica:

A reestruturação, em seu sentido mais amplo, transmite a noção de uma 'freada'[...] e de uma mudança em direção a uma ordem e uma configuração significativamente diferente da vida social, econômica e política. Evoca, pois, uma combinação sequencial de desmoronamento e reconstrução, de desconstrução e tentativas de reconstituição, proveniente de algumas deficiências ou perturbações nos sistemas de pensamento e ação aceitos. (SOJA, 1993, p.193) 
2 É verdade que observar a reestruturação econômica nos obriga a identificar diferentes escalas geográficas e tipos de determinações sobre uma área estudada. Uma vez que um determinado recorte espacial passa a assumir este papel de objeto, enquanto foco de uma investigação sobre a reestruturação econômica que ali ocorre, é preciso reconhecer a existência de múltiplas determinações atravessando esta área. É fundamental reconhecer tanto os efeitos das diferentes escalas geográficas que incidem sobre a área quanto as causalidades que partem do funcionamento sistêmico do capitalismo. Tomamos aqui como base os estudos do caráter cíclico da geo-histórico do capital de Giovanni Arrighi (1996).

3 As raízes sistêmicas presentes nos processos de reestruturação econômica ao redor do mundo inevitavelmente influenciam este processo, de maneira mais ou menos decisiva - a depender área geográfica. $O$ espaço da reestruturação é concreto e empírico em sua resultante regional, mas definição passa necessariamente pelas contradições da produção capitalista do espaço. E é interligando as contradições do espaço capitalista, com sua funcionalidade sistêmica no decorrer de suas experiências geo-históricas, que avaliamos ser possível uma reflexão crítica a partir da geografia.

4 Optamos então por seguir um roteiro que se inicia na compreensão das transformações que ocorrem no regime fordista-keynesiano no último terço do século, elencando seus êxitos e debilidades enquanto modelo de organização da acumulação capitalista. Para então, em sequência, desenvolver comparações com os casos semelhantes de reestruturação capitalista no decorrer dos longos séculos, periodizados por Arrighi (1996), mas sem esquecer das diferenças próprias de cada experiência capitalista no espaço-tempo. Por fim, ao alcançar constatações resultante deste movimento de comparação, é possível enumerar características e padrões que persistem nestas reestruturações capitalistas, habilitando o entendimento deles enquanto causas ou raízes sistêmicas destas transformações nos meios de acumulação.

5 A Reestruturação do Regime Fordista-Keynesiano

Existe um grande consenso, dentro da literatura preocupada com a análise das variações do capitalismo no tempo-espaço, relacionado às transformações que ocorreram após as crises econômicas das décadas de 1970. É notória a existência de uma ruptura nos padrões dos meios de acumulação do capital que predominaram o período que se sucedeu ao fim da Segunda Guerra Mundial (1939-1945). Toda a glória das políticas macroeconômicas keynesianas ${ }^{1}$ e do modelo fordista de produção ${ }^{2}$, historicamente compreendidos como salvação econômica frente a pavorosa crise de 1929, parece insuficiente diante dos limites encontrados mais recentemente em sua própria operacionalidade. As explicações para esse giro na chave de condução do sistema capitalista são inúmeras e assumem também a forma de narrativas culturais, como a própria crítica pós-moderna. Contudo, entendemos que são as modificações nos padrões dos meios de acumulação de capital que habilita as condições materiais para uma cadeia de alterações sociais.

o fator central do fordismo-keynesiano estava em sua compreensão de que "algum grau de ação coletiva - de modo geral, a regulamentação e a intervenção do Estado - é necessário para compensar as falhas de mercado" (HARVEY, 1992, p. 118). O Estado passaria a assumir papéis mais amplos na disciplina do processo de trabalho, na adequação de algumas formas de monopólio e no controle do mercado. Além da invenção de uma nova conduta moral do trabalhador, algo que já vinha sendo desenhado pelo próprio Henry Ford ${ }^{3}$, houve também um forte controle e 
burocratização dos sindicatos - que se viam obrigados a abrir mão de ganhos salariais em troca de estabilidade do sistema. Por outro lado, é registrado uma melhora nas condições de vida da classe trabalhadora, principalmente a estadunidense, ainda que isto não se confirme na realidade econômica de outros países. O maior controle das relações salariais pelo Estado foi determinante para manter o consumo estável, pois o grande motor do regime era a produção de mercadorias em proporções cada vez maiores, de modo que esta precisava ser acompanhada pela intensa ampliação do consumo.

7 Ao voltarmos nossos olhos para a maneira como se desenvolveu a produção em massa fordista-keynesiana, devemos enxergar mais do que um método de gerenciamento do trabalho elaborado por Henry Ford. O controle meticuloso do tempo ao longo da jornada de trabalho, os postos de trabalhos fixos e bem divididos, dentro de um mesmo ritmo, foram importantes para os ganhos de produtividade. No entanto, ela sozinha não teria assegurado o êxito dos anos de relativa estabilidade econômica entre 1950 e 1973. Compreender os elementos virtuosos deste período passa também por reconhecer tanto a situação econômica internacional, quanto o papel inovador das grandes corporações. o dólar enquanto câmbio fixo internacional, sem cotações diárias e atrelado ao padrão ouro, veio a se tornar um regime monetário capaz de proporcionar investimentos e termos de troca vantajosos para o Estados Unidos, seja com países periféricos exportadores de matéria-prima, seja com os países centrais que sofreram drasticamente com a Segunda Guerra Mundial:

o longo período de expansão do pós-guerra dependia de modo crucial de uma maciça ampliação dos fluxos de comércio mundial e de investimento internacional.

[...] Essa abertura do investimento estrangeiro (especialmente na Europa) e do comércio permitiu que a capacidade produtiva excedente dos Estados Unidos fosse absorvida alhures, enquanto o progresso internacional do fordismo significou a formação de mercados de massa globais e a absorção da massa da população mundial [...]. (HARVEY, 1992, p. 131)

8 Podemos traçar um rápido paralelo entre a extensa destruição de recursos ao longo da Segunda Guerra, iniciada como disputa política e econômica entre as potências europeias, e a dinâmica de desvalorização descrita por Harvey (2005) ao tratar da geopolítica do capitalismo. Ao abordar questões envolvendo circulação e crises do capital, ele descreve como a existência do excedente econômico desencadeia uma desvalorização (inflação, perda de capacidade produtiva, seguridade, renda real dos trabalhadores) quando não absorvido de alguma forma. Ele ainda utiliza o exemplo das disputas entre diferentes regiões ou cidades dentro do mercado mundial, assumindo que este confronto produz um processo de exportação de desvalorização para as regiões que não alcançam saídas para a realização de seus excedentes. Sabemos que a Segunda Guerra não se equivale a disputas regionais dentro da economia globalizada, mas é inegável que a desvalorização resultante dela proporcionou benefícios igualmente, ou até mais, satisfatórios para o dilema dos excedentes de capital. Além de ter aberto uma avenida de mercado para o arranque produtivo dos Estados Unidos.

9 Ao mesmo tempo, "a América [Estados Unidos] agia como banqueiro do mundo em troca de uma abertura dos mercados de capital e de mercadorias ao poder das grandes corporações" (HARVEY, 1992, 131). Qual seria, afinal, o grande diferencial destas corporações enquanto forma de organização empresarial e capitalista? Harvey (1992) destina sua atenção para a alta capacidade de centralização de capital e de poder nas mãos destas corporações. Sendo vista como um conglomerado de empresários que 
atuavam em acordo com o Estado, na busca pelo refreamento das concorrências intercapitalista através do planejamento a longos prazos e adoção de preços monopolistas (HARVEY, 1992, p. 129). Entretanto, elas foram mais do que as grandes investidoras do processo de produção em massa e da separação entre propriedade e gestão, elas alteraram a lógica geográfica do capitalismo neste período. Giovanni Arrighi (1996), em O Longo Século XX, descreve muito bem as vantagens espaciais deste "capitalismo de corporações" (ARRIGHI, 1996, p.296) que emerge nos Estados Unidos desde o final do século XIX:

Nos Estados Unidos, em contraste [com o mesmo processo na Alemanha], o grande movimento de centralização do capital dirigiu-se à integração vertical. [...] Assim, os custos de transação, os riscos e as incertezas envolvidos na movimentação de insumos e produtos ao longo das sequências desses subprocessos foram internalizados em empresas formadas por várias unidades separadas, sendo submetidos à lógica econômica da ação administrativa e do planejamento empresarial a longo prazo. (ARRIGHI, 1996, p.296)

10 As corporações, diferente das empresas britânicas altamente especializadas em um único processo fabril e amplamente dependente do beneficiamento e dos insumos fornecidos por suas colônias e demais países, internalizaram todo processo produtivo em seus domínios. Essa integração vertical das corporações passa então a substituir o mercado em certo aspecto, por se esquivar de possíveis flutuações de preços e crises econômicas regionais, já que elas mesmas controlam as etapas produtivas anteriores ao seu produto final. Soma-se a isto os avanços tecnológicos na redução do custo de transação intrafirma e veremos o aumento da concentração industrial nos Estados Unidos sob a forma do Rust Belt ${ }^{4}$ no nordeste do país. Os parques industriais desta época refletem geograficamente toda a força que a concentração industrial trazia tanto para o planejamento a longo prazo quanto para a redução dos custos de produção. Com isso, é notável que as corporações foram uma das peças mais centrais do regime fordistakeynesiano.

11 O interessante da abordagem de Giovanni Arrighi (1996) está em sua percepção do fordismo enquanto mais uma fase transitória do capitalismo, descrevendo o arranjo geográfico e político que se desenvolve neste período - ainda que esta não seja sua maior questão. Mas isso só adquire nitidez na medida em que avançamos na sua compreensão sobre o que é o capitalismo e como tem funcionado seu desenvolvimento geo-histórico. O conceito chave de Arrighi (1996) é o de ciclos sistêmicos de acumulação, que carrega consigo tanto uma proposta de periodização do capitalismo, quanto de estruturação do próprio sistema econômico a nível mundial. Estes ciclos sistêmicos também são descritos por ele como longos séculos, com durações que podem chegar até mais de 200 anos. Além disso, são a combinação entre os diferentes patamares evolutivos da acumulação do capital e os ascensos (e posteriores quedas) de diferentes países ao papel de liderança econômica e territorial responsável pela dianteira da manutenção do moderno sistema mundial (ARRIGHI, 1996, p.32).

\section{Uma Geo-história dos Ciclos Sistêmicos de Acumulação}

12 O regime fordista-keynesiano significou uma parte do quarto ciclo sistêmico, ou longo século estadunidense. Antes deste, houveram ainda os ciclos genovês, holandês e britânico, seguindo a ordem cronológica, "[...] cada qual caracterizado por uma unidade 
fundamental do agente e estrutura primários dos processos de acumulação de capital em escala mundial" (ARRIGHI, 1996, p.6). A extensão final de cada ciclo coincide com o surgimento de um novo, não havendo uma relação de superposição e sim de sobreposições, o mural completo disso é "[...] compostos de fases de mudanças contínuas, que seguem uma via única, alternando-se com fases de mudanças descontínuas, que vão de uma via para outra [...]" (ARRIGHI, 1996, p. 9). Com isso é possível perceber que existe uma sequência, que combina rupturas, ao longo de uma mesma onda de expansão do sistema capitalista. Esta percepção em profundidade na geo-história do capital nos permite avançar na visualização do marco inicial da reestruturação capitalista a partir da década de 1970, de uma maneira diferente da feita por Harvey (1992), e de uma perspectiva mais relacional de tempo:

As indagações que geraram este estudo são semelhantes às de Harvey [1992]. Mas as respostas são buscadas numa investigação das tendências atuais à luz dos padrões de repetição e evolução que abarcam todo o curso do capitalismo histórico como sistema mundial. Uma vez que ampliemos dessa maneira o horizonte espaçotemporal de nossas observações e conjecturas teóricas, tendências que pareciam inéditas e imprevisíveis começam a afigurar-se familiares. (ARRIGHI, 1996, p. 4)

13 Ou seja, o regime fordista-keynesiano carrega consigo semelhanças com outros momentos da expansão sistêmica do capitalismo e, por consequência, seus respectivos ciclos sistêmicos de acumulação anteriores. Uma das chaves para essa análise relacional entre os ciclos está no reconhecimento de um padrão na forma como o capitalismo realizou sua expansão econômica até os dias de hoje. Arrighi identifica dois tipos de expansão, que se intercalam no interior de um ciclo sistêmico. São eles os períodos de expansão material e os períodos de expansão financeira. Havendo então períodos de maior facilidade para os investimentos sistemáticos na esfera da produção, o fordismo é um exemplo, e outros períodos de maior flexibilidade nas destinações do capital, que passa a se abrigar em maior proporção nos rendimentos das finanças e a desacelerar seu ritmo produtivo.

Assim, mostraremos que as fases DM, de expansão material, consistem em fases de mudanças contínuas, durante as quais a economia capitalista mundial cresce por uma única via de desenvolvimento. E veremos que as fases MD', de expansão financeira consiste em fases de mudanças descontínuas, durante as quais os crescimento pela via estabelecida já atingiu ou está atingindo seus limites e a economia mundial 'se desloca', através de reestruturações e reorganizações radicais, para outra via. (ARRIGHI, 1996, p.9)

14 Essa passagem já nos transmite um pouco das compreensões do autor sobre o próprio processo de reestruturação capitalista, mas nosso ponto aqui é pontuar o quanto sua reflexão favorece uma interpretação ampla sobre as transições entre regimes de acumulação. Inserindo o caso estadunidense, do fordismo-keynesiano, dentro de uma contexto de ciclos sistêmicos e agregando à ele um sentido ainda mais complexo e correlacionado. A passagem para o atual regime de acumulação pode ser analisada então em comparação com as demais reestruturações pretéritas, ressaltando assim a causalidade sistêmica atuante em cada situação, em cada ciclo.

Ao nos depararmos com o primeiro ciclo de acumulação, vemos parte da aristocracia de Gênova $^{5}$ assumindo características semelhantes aos dos capitalistas modernos e adentrando a lógica das finanças e do lucro ao fundarem a Casa de San Giorgio em 1407, comprando dívidas de guerra do Estado. Estes, também conhecidos como Nobili Vecchi, eram negociantes preocupados com a ampliação de excedentes e investiram na compra de áreas rurais próximas e no comércio a longas distâncias. Entretanto, o regime feudal 
e o recrudescimento de alguns membros desta classe ao perfil de senhor feudal debilitou a influência destes financistas genoveses dentro do Estado. $\mathrm{E}$ após a perda de muitas rotas de comércio no Mar Negro, fruto da derrota na Guerra de Chioggia para Veneza, os Nobili Vecchi foram obrigados a reorganizar seus investimentos (ARRIGHI, 1996, p. 115-123). Ao apostar nos portos e nas rotas marinhas ao sul da Península Ibérica, no entanto, eles aproveitaram muito bem a falência de grandes bancos privados em Barcelona, na Espanha da década de 1340. A derivação final do exitoso comércio e relação com a Espanha foi a fase de expansão material do ciclo genovês.

o fator decisivo para a ascensão dos financistas genoveses estava no custo de proteção requerido pelos investimentos, uma vez que seu próprio Estado não detinha condições territoriais ou militares para assegurar uma ampla expansão das possibilidades de comércio. Por outro lado, a Espanha era justamente um Estado interessado em se expandir territorialmente, com recursos de defesa, mas com fundos monetários insuficientes. O casamento entre estes dois fez com que o "[...] componente territorialista criou oportunidade comerciais lucrativas para o componente capitalista e, por outro, a busca de lucro por este último fortaleceu a eficácia e a eficiência do aparelho produtor de proteção do componente territorialista" (ARRIGHI, 1996, p.124). O resultado disso foi a ampliação do mercado mundial através das grandes navegações e a colonização na América. Foi a exploração da prata nas colônias espanholas e o comércio de metais na Europa, que fizeram o sucesso da expansão material genovesa. A família Fugger passa então a ganhar destaque entre os banqueiros genoveses por converter as dívidas do rei espanhol Carlos $\mathrm{V}$ em direitos ou posses de mineração nestas novas áreas (ARRIGHI, 1996, p.125-128).

17 O exemplo do primeiro ciclo demonstra o quão fundamental é a garantia da defesa territorial na viabilidade de uma expansão material sistêmica. Nenhum financista genovês aceitaria ser pago com direitos de mineração se não houvesse um grande aparato de defesa de seus investimentos. Este comércio da prata seria a grande fonte de ouro para os Nobili Vecchi nos mercados de Antuérpia, servindo de excedente também para a nova expansão financeiras que durou até o começo do século XVII. Ao avançarmos para o segundo ciclo de acumulação, da Holanda, vemos que este surge a partir de reações aos abusos tributários aplicados pela Espanha. A mesma força territorial e econômica adquiridos do primeiro ciclo, entretanto, acabou exibindo suas contradições e seu peso administrativo, revelando um resultado oposto em sua tentativa de ampliação das cobranças e taxas:

Os rebeldes holandeses fizeram-se ao mar e desenvolveram habilidades extraordinárias, não só na evasão fiscal, mas em impor às finanças da Espanha Imperial uma espécie de arrocho fiscal 'invertido', através da pirataria e da pilhagem. (ARRIGHI, 1996, p.135)

18 A escalada econômica da Holanda passou por dois movimentos concomitantes: a) a expropriação e a evasão de divisas do comércio marítimo espanhol, por um lado; b) o comércio de suprimentos e grãos para toda a Europa durante o acirramento dos conflitos na Guerra dos 30 Anos (1618-1648), por outro. As disputas por mercado e a concorrência no continente europeu foram acentuadas pelas novas proporções alcançadas nas colonizações e pelo declínio da Espanha enquanto potência inalcançável. A situação de crise se transformou em oportunidade para os holandeses e o comércio no Báltico se beneficiou, mesmo sem grandes aumentos no volume de grãos vendidos, da escassez de gêneros alimentícios e do aumento relativo de preços (ARRIGHI, 1996, p. 137). A expansão material deste ciclo, entretanto, só viria a acontecer após o 
estabelecimento do Tratado de Vestfália ${ }^{6}$ e da redução dos conflitos armados no continente, propiciando estabilidade para o aumento do comércio. 0 reinvestimento em terras e na agricultura consolidou o desenvolvimento regional do país, mas não significou sua estagnação ou recuo nos investimentos a nível de mercado mundial, pelo contrário, a burguesia holandesa conseguiu

[...] transformar Amsterdam não apenas no armazém central do mercado mundial [de suprimentos], mas também no mercado central de moedas e capital da economia mundial européia. $O$ principal movimento tático nesse aspecto foi a criação, em Amsterdam, da primeira bolsa de valores com pregão permanente.

(ARRIGHI, 1996, p.142)

19 Para coroar sua fase de expansão material, houve a instituição de companhias de comércio e navegação de grande porte, para fixar controles militar sobre determinadas rotas de comércio e exercer exploração sobre outros povos, através da Companhia Holandesa das Índias Orientais (VOC) e Companhia Holandesa das Índias Ocidentais (WIC). Esta última, inclusive, foi responsável pela tentativa de invasão em Salvador (1624), então capital do Brasil colônia, e pela ocupação de Pernambuco em seguida, entre 1630 e 1654 . Ao passo em que os holandeses buscavam o monopólio do comércio a longas distâncias, eles também ampliaram a escala do mercado mundial e estabeleceram sua própria rede comercial e financeira (ARRIGHI, 1996, p.143). Esta rede foi extremamente decisiva para o período seguinte de expansão financeira, após os meados do século XVIII. E, diferente do ciclo genovês, a Holanda garantiu a própria proteção de seus investimentos materiais e produtivos, traduzindo posteriormente sua expansão material em uma estrutura financeira muito mais veloz e consistente.

Um dos fatores responsáveis pelo declínio deste segundo ciclo de acumulação fora justamente a tentativa e o êxito dos outros países em adotar o modelo e a lógica econômica dos holandeses, estas mudanças alcançadas pelos concorrentes ficaram conhecidas como mercantilismo (ARRIGHI, 1996, p.145). Essa nova forma de lidar com a questão econômica nacional teve rebatimentos sobre a predominância holandesa e seus monopólios comerciais, sob a forma de substituição de importações provenientes desta. Algo semelhante ocorreu também com o regime fordista-keynesiano, na medida em que as economias dos outros países se recuperavam e absorviam as técnicas e os modos de regulação inaugurados no ciclo estadunidense. Contudo, a relativa indissociabilidade entre os interesses econômicos e os interesses territoriais que potencializaram a Holanda em seu longo século, rendendo a ela grandes vantagens, agora dificultava sua relação com as Companhias autárquicas, que se burocratizam e articulavam seus próprios interesses.

21 Ironicamente, as condições sistêmicas para o ciclo de acumulação inglês também têm raízes na pilhagem e nas incursões de corsários piratas, sem as quais não seria possível, tão rapidamente, quitar suas dívidas externas e financiar as Companhias do próprio país. O famoso galeão Golden Hind, assim rebatizado pelo seu novo capitão Francis Drake, por exemplo, teria alçado retornos estimados em $£ 600.000$, habilitando a rainha Elisabeth à destinar $£ 42.000$ para a consolidação da Companhia do Levante, precursora da Companhia das Índias Orientais inglesa (ARRIGHI, 1996, p.191). Em paralelo a estes antecedentes, soma-se a criação da Real Bolsa de Valores após a crise econômica de Antuérpia (1557-1562), uma iniciativa sugerida por Thomas Gresham, aceita por Elisabeth, e que marcou o início do nacionalismo nas altas finanças (ARRIGHI, 1996, p. 195). Esse movimento antecipou em muito o papel financeiro hegemônico que o país viria a cumprir durante seu ciclo sistêmico, a partir dos meados do século XVIII, e foi 
decisivo para a viabilização da política de moeda forte e estável - atrelada ao padrão ouro - que viria a se tornar a marca registrada da política econômica inglesa.

A expansão material do ciclo inglês, entretanto, só encontraria suas condições sistêmicas e uma conjuntura estável, capaz de habilitar uma ampliação comercial motivada por uma crescente produtividade, no século XIX, durante a Paz de Cem Anos da Grã-Bretanha, de 1815 até 1914 (ARRIGHI, 1996, p.174). Este período tem como marco inicial o Tratado de Paris, que diluiu os conflitos no continente europeu e competições extremadas associadas às Guerras Napoleônicas (1803-1815), e encontrou seu limite com o início da Primeira Guerra Mundial. Portanto, foi um intervalo mais que necessário para a expansão material do ciclo inglês. O que resultou também na consolidação do capitalismo enquanto modo de produção hegemônico no país, realizando uma nova rodada de expansão comercial e de exploração de recursos.

É verdade que cada ciclo sistêmico de acumulação tem significado consecutivas ampliações das funcionalidades capitalistas e da lógica do lucro, mas é apenas em seu terceiro longo século que ele alcança sua maturidade enquanto sistema econômico. Isso fica explícito inclusive em termos bibliográficos, pela quantidade de pensadores que reconhecem a Revolução Industrial inglesa como marco inaugurador do capitalismo, não tão preocupados em enxergar essa transição desde feudalismo ${ }^{7}$. Quando em 1867 , Karl Marx lançava o livro um de O Capital, inaugura-se uma crítica concisa sobre o funcionamento do recém-nascido modo de produção capitalista. Após retirar as condições de sobrevivência de seus camponeses, privatizando suas terras e os expulsando para os centros urbanos, a Inglaterra disciplina e incide na formação de uma nova classe de exploráveis, o proletariado (MARX, 2013, p.785-833). A relação de produção que surge deste processo consiste em esconder a apropriação dos frutos do trabalho empreendido pelo proletariado nas fábricas sob a forma de uma pretensa relação igualitária entre o dono dos meios de produção (burguês) e o dono da força de trabalho (proletário), que resulta na troca de um salário por uma jornada de trabalho:

Como a produção de mais valor é o objetivo determinante da produção capitalista, o que mede o grau de riqueza não é a grandeza absoluta do produto [seu valor], mas a grandeza relativa do mais-produto [parte do valor do produto que não foi remunerada]. A soma do trabalho necessário e do mais-trabalho, isto é, dos períodos em que o trabalhador produz o valor de reposição de sua força de trabalho [correspondente ao seu salário] e o mais-valor, constitui a grandeza absoluta de seu tempo de trabalho - a jornada de trabalho (working day). (MARX, 2013, p.304)

A responsabilidade pela sobrevivência da classe que executa o trabalho é abandonada pelo Estado e pelos capitalistas sob a máscara do salário. Essa invenção rendeu ao ciclo inglês uma expansão material avassaladora, o mais-valor obtido do proletariado e o constante reinvestimento de capital na produção alavancou avanços tecnológicos sem precedentes. O maquinismo que surge neste momento, com o tear mecânico e descaroçador de algodão, além de um sistema de transportes sustentado por ferrovias e barcos a vapor, baseiam-se na combustão do carvão mineral e nas caldeiras para intensificar a acumulação e a produção de bens industrializados (MOREIRA, 2016, p.64). A apropriação de riquezas e de rendimentos em outros meios de produção e outros territórios, caminho único para os ciclos genovês e holandês, soma-se então à um novo motor essencialmente capitalista, construído por ele mesmo e síntese da ascensão política da classe capitalista ou burguesia: o modo de produção capitalista.

25 Assim, “[...] o regime britânico unilateral de livre comércio ligou o mundo inteiro à Grã-Bretanha. Esta se tornou o 'mercado' mais conveniente e eficiente para obter meios 
de pagamento e de produção e para colocar produtos primários" (ARRIGHI, 1996, p.169). Ou seja, uma divisão internacional do trabalho muito firme se estabeleceu, de um lado a Inglaterra exportando bens de capital (maquinário, infraestrutura ferroviária, equipamentos, meios de transportes) e bens manufaturados, do outro as colônias e os países não industrializados exportando todos os insumo e produtos primários. Uma integração técnica e produtiva foi sendo estabelecida na medida em que a Inglaterra foi espraiando seus mercados e suas influências comerciais e políticas. Mas a contradição dessa situação, de aproveitamento das desigualdades econômicas reforçadas por sua estruturação imperialista, foi a dependência de matérias-primas provenientes de determinados lugares e a dispersão dos recursos necessários à perpetuação de seus avanços industriais:

Na primeira metade do século XIX, na Inglaterra, a mais valia saía do processo de produção, em sua maior parte, em forma de tecido de algodão. Os elementos materiais de sua capitalização, porém eram: algodão procedente dos Estados escravistas da União americana; os cereais (meios de subsistência para os operários ingleses) procedentes dos campos russos constituídos de servos da gleba [...]. O fato da acumulação capitalista depender desses meios de produção, não produzidos pelo capitalismo, é demonstrada pela crise algodoeira inglesa gerada durante a Guerra da Secessão americana [...]. (LUXEMBURGO, 1970, p.306)

Assim como Gênova, Holanda e Inglaterra, os Estados Unidos também foi o agente territorial que melhor aproveitou o final do ciclo sistêmico anterior, que ainda mantinha um fôlego econômico devido à sua atuação nas altas finanças, mas que acabava recaindo em turbulências até sua crise final (ARRIGHI, 1996, p.220). Por mais que a Inglaterra tivesse arcado militarmente com a manutenção de seu imperialismo e sua influência a favor da liberalização cambial dos outros países, sua exportação de capitais e de força de trabalho (visando espaços com potencialidades produtivas) para suas colônias estimulou novos centros econômicos e possíveis novos concorrentes ${ }^{8}$. E é em decorrência disto que o desenvolvimento produtivo dos Estados Unidos viria a ser erguido e reconhecido futuramente como Segunda Revolução Industrial, iniciando justamente no intervalo de tempo da expansão financeira inglesa:
A segunda revolução industrial começa nos Estados Unidos por volta de 1870, [...] uma divisão territorial do trabalho bastante ramificada, cujos setores simbólicos são a metalurgia, a eletrodinâmica e a petroquímica, como ramos da indústria, e a eletricidade e o petróleo, como ramos de energia, combina-se a um sistema de maquinismo de alta escala de concentração técnica. (MOREIRA, 2016, p.67)

Essa nova expansão material e novo patamar do modo capitalista de produção, no entanto, só viria a se firmar após mais uma escalada das lutas competitivas entre os países que emergiram com a desaceleração da economia inglesa. Com isso, "na medida em que a Alemanha mobilizou seu poderoso aparato militar-industrial em sua busca de Lebensraum [espaço vital], a viabilidade do regime de acumulação britânico foi irremediavelmente minada" (ARRIGHI, 1996, p.300). Não é preciso ir muito longe para constar que, assim como houve uma depreciação dos termos gerais de troca em todos os outros conflitos presentes no final dos ciclos sistêmicos anteriores, a culminância destas disputas destrutivas foi a deflagração da Primeira e da Segunda Guerra Mundial. A estabilidade econômica só viria a ser retomada, assim como ocorreu posteriormente aos tratados de Vestfália e de Paris, com a criação de um novo modo de regulação das relações políticas e econômicas internacionais, que emergem após o Acordo de Bretton Woods em 1944 (ARRIGHI, 1996, p.287). 
28 Ao lado da criação da Organização das Nações Unidas e do Fundo Monetário Internacional, um novo sistema monetário se organizou com base no dólar, mas mantendo ainda um lastro no padrão ouro, herdando o princípio da moeda forte do ciclo inglês. Não apenas “[...] os Estados Unidos atuaram como oficina do esforço de guerra dos Aliados e como celeiro e oficina da reconstrução europeia do pós-guerra" (ARRIGHI, 1996, p.284), como também estabilizaram os fluxos financeiros através de Wall Street. A expansão material estadunidense, por conseguinte, se organizou espacialmente de maneira a evitar justamente os fatores que levaram a Inglaterra à sua decadência produtiva e comercial:

Essa estrutura das empresas britânicas - muito extrovertida, descentralizada e diferenciada - constituiu um grande obstáculo a sua organização em corporações, nos moldes alemães ou norte-americanos. Não apenas ela dificultava as integrações horizontais para restringir a competição, [...] como também impedia as empresas britânicas de aproveitarem as oportunidades de reduzir os custos unitários, através de um planejamento mais rigoroso e da integração das atividades sequenciais em que se dividiam os processos de produção e comercialização [...]. (ARRIGHI, 1996, p. 292)

29 O regime fordista-keynesiano, ou expansão material do ciclo estadunidense, resolveu a dispersão produtiva e comercial do imperialismo inglês através da centralização dos subprocessos ligados às atividades industriais, sob o molde das corporações - como já vimos. Além disso, aprofundou exponencialmente todos os processos inaugurados no ciclo inglês, como a redução do tempo de giro do capital, a globalização da economia mundial e estruturou sua própria forma de imperialismo (HARVEY, 2014). O sistema prosseguiu com sua expansão não apenas acirrando o controle sobre os trabalhadores e elaborando novas infraestruturas e tecnologias (MOREIRA, 2016, p.89). Ele proporcionou uma escala de atuação ainda maior para o modo de produção capitalista, via corporações multinacionais, e também difundiu um novo modelo de Estado e de regulação econômica. Assim como o mercantilismo foi a forma encontrada pelos outros países europeus para copiar os acertos do ciclo holandês, o desenvolvimentismo industrial orientado pelo Estado se tornou um exemplo a ser seguido pelos demais países.

\section{A Reestruturação nas Expansões Materiais e Financeiras}

30 Após essa retrospectiva geo-histórica acerca dos ciclos sistêmicos de acumulação, em um esforço de traçar paralelos entre suas respectivas transições no fim de cada expansão material, devemos nos atentar também para a grande diferença de nível de complexidade entre eles (ARRIGHI, 1996, p.222). Os dois primeiros ciclos expressam o momento mais embrionário do sistema capitalista, mas que já apresenta sua característica flutuabilidade, ao mesmo tempo em que esbarra com as correntes do feudalismo. O ciclo estadunidense, no qual nos encontramos, complexificou não apenas o modo de produção capitalista inaugurado na Inglaterra, mas principalmente as dinâmicas envolvendo a expansão financeira. Atualmente, o crescimento do setor financeiro dispara muito na frente, em proporções múltiplas, do crescimento do setor produtivo, algo inédito de certa forma.

31 Para alcançarmos um patamar de síntese é necessário reconhecer que existem condições para o surgimento de um período de expansão material e que, ao observar a 
linha cronológica do conjunto dos ciclos, estes momentos foram mais exceção do que regra, em termos de duração. Essas condições são sistêmicas e evoluem se complexificando, na medida em que o sistema capitalista se prolonga e amplia a proporção de seus excedentes. Podemos então enumerar alguns pontos comuns das expansões materiais até o momento: a) presença de um agente territorial capaz de garantir a proteção dos investimentos de capitais e da propriedade privada - até o momento foi o Estado; b) estabilização dos conflitos provenientes das disputas internacionais estimuladas pelo processo de queda do ciclo anterior; c) consequente estruturação de uma rede financeira e comercial, necessária à próxima fase do ciclo; d) consequente inovação das técnicas e do modelo de produção e de circulação das mercadorias; e) resulta em um processo de reestruturação em dimensões mundiais, mas correlacionado com reestruturações em escala regional.

O significado das diferenças entre a expansão material e a expansão financeira está muito mais vinculado à geografia e às formas dos mecanismos para empreender a acumulação do que com uma mudança na essência do próprio sistema. Por suposto, existe uma relação decisiva entre o destino do capitalismo e as formas que ele encontra para realizar sua acumulação, mas suas flutuações precisam necessariamente estar presente na reflexão sobre deste paradigma. A rigidez do modelo fordista estadunidense, resguardada a parcela correspondente à especificidade do modelo que se estabeleceu ali, carrega consigo as virtuosidades e os limites correspondentes à um regime de acumulação favorecido pela tendência produtiva. Ou seja, os investimentos em capital fixo e a aglomeração econômica, fruto de constantes injeções de novos capitais, justificam-se pelo fato de haver um grande retorno de excedente. Contudo, as vantagens de uma expansão material e do modelo fordista-keynesiano precisa lidar em algum momento com os embaraços de espacializar seus investimentos em uma larga escala industrial.

33 Ao corporificar o capital massivamente em meios de produção fixados ao solo, o regime fordista-keynesiano acaba por acentuar exponencialmente a contradição da produção do espaço capitalista que se refere ao sucateamento do capital fixo. "A paisagem geográfica, abrangida pelo capital fixo e imobilizado, é tanto uma glória coroada do desenvolvimento capitalista passado, como uma prisão inibidora do progresso adicional da acumulação [...]" (HARVEY, 2005, p.51). Este efeito inerente ao modo de produção capitalista, acentua-se também com o advento da redução do tempo de giro do capital e da diminuição da dependência localizacional ${ }^{9}$ da indústria, ambos proporcionados pelos avanços tecnológicos e logísticos na esfera da circulação. Com isso, toda a reestruturação econômica pós-1970 acaba por refletir com ainda mais força a demanda por flexibilidade, dinamismo e a busca constante por localizações vantajosas à redução dos custos de produção:

A mudanças tecnológica, a automação, a busca de novas linhas de produto e nichos de mercado, a dispersão geográfica para zonas de controle do trabalho mais fácil, as fusões e medidas para acelerar o tempo de giro do capital passaram ao primeiro plano das estratégias corporativas de sobrevivência em condições gerais de deflação. (HARVEY, 1992, p.137-140)

As disputas entre capitalistas, na cotidiana corrida pela realização de seus produtos nos mercados, foram sim alavancadas por um acirramento da concorrência internacional e pelas inovações tecnológicas. Entretanto, todas essas alterações passam por dentro da flutuabilidade sistêmica que estamos observando. Se o modo de produção capitalista encontrou maiores dificuldades, isso pode representar tanto um processo de mudança 
das condições materiais da produção quanto uma alteração sistêmica em escala mundial. O fim do sistema de Bretton Woods, a desvinculação do dólar em relação ao padrão ouro, o modelo de taxas de câmbio com flutuações diárias, a desregulamentação financeira, todas estas medidas econômicas tiveram rebatimentos sobre os aspectos materiais da esfera produtiva (ARRIGHI, 1996, p.321-331). O processo de expansão financeira redefine as prioridades da acumulação, mas com isso redefine também os termos da exploração da força de trabalho e da concorrência no mercado.

35 A fragmentação do processo produtivo através da multiplicação de empresas que fornecem serviços parciais na cadeia produtiva carrega consigo as virtudes de uma organização espacial que já vista no passado. A horizontalidade produtiva permite flexibilidade nas decisões na esfera da produção, mas diferente de antes, com as novas tecnologias de comunicação, o dinamismo destas mudanças ocorre em uma proporção e em um intervalo de tempo mais perto do instantâneo. Contudo, os riscos deste arranjo produtivo ainda persiste na medida em que as disputas entre os países podem resultar em retaliações comerciais ou em medidas que elevam os custos desta forma de organizar o espaço capitalista. Outro paralelo, entre a expansão financeira atual e as expansões financeiras passadas, pode ser feito entre a desregulação neoliberal impulsionado pela Escola Austríaca e o capitalismo informal que prosperou nos séculos XVI e XIX, nas expansões financeiras genovesa e inglesa (ARRIGHI, 1996, p.341).

Outro esforço de periodização geo-histórica destes processos de reestruturação ao longo dos séculos está presente em Edward Soja (1993), ao abordar o processo de reestruturação observando a evolução urbana que ocorreu nos Estados Unidos entre 1820 e 1970 (Imagem 1). Os quatro protótipos de espacialização urbana “[...] podem ser vistas como 'estratificação', uma em cima da outra, refletindo mudanças pronunciadas nas geografias do investimento, da produção industrial, do consumo coletivo e da luta social" (SOJA, 1993, p.212). Como nosso foco é a causalidade sistêmica nisso tudo, podemos assumir que essas fases do processo de reestruturação urbano-econômica trazidas pelo autor foram influenciadas: na primeira fase (1820), pelo crescente comércio com a Inglaterra, com a ascensão de sua expansão material; na segunda fase (1870), pela passagem para o período de expansão financeira do ciclo inglês; na terceira fase (1920), pelo nascimento do regime fordista-keynesiano, ou expansão material estadunidense; na quarta fase (1970), pela passagem para a atual etapa de expansão financeira.

As datações de cada reestruturação, com sua respectiva forma urbana, coincidem bastante com as passagens entre os dois tipos de expansão dentro de um ciclo sistêmico. Contudo, isso não significa que Soja (1993) tenha levado os fatores sistêmicos em conta, principalmente se observarmos os nomes dados a cada uma dessas fases. São os elementos associados ao processo de urbanização que explicam e definem a passagem da cidade mercantil para a cidade industrial de livre concorrência, desta para a cidade do monopólio empresarial e por fim, na última fase, a cidade administrada pelo Estado fordista. A ênfase dada por Soja (1993) está nas determinações regionais e urbanas relativas ao processo de reestruturação, mas sua análise acaba se deparando com fenômenos influenciados também pelos fatores sistêmicos ${ }^{10}$. É necessário reconhecer que ambas as causalidades se combinam e se influenciam mutuamente e que as escolhas analíticas e o método adotado dizem muito mais sobre a narrativa construída para interpretar a realidade. 
Imagem 1: Evolução do arranjo urbano das cidades estadunidense de 1820 a 1970.

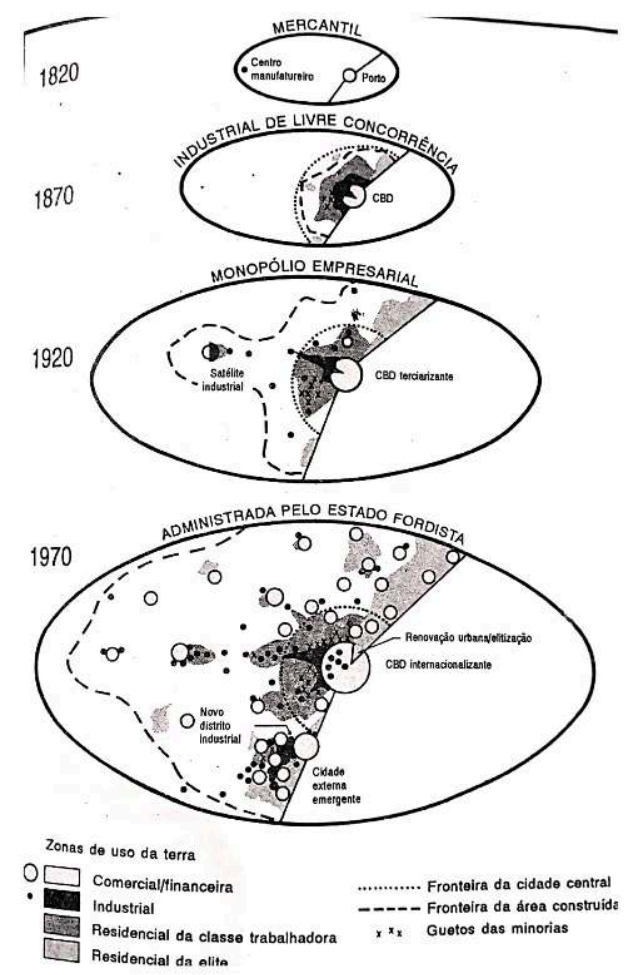

Fonte: SOJA, Eduard. Geografias Pós-Modernas, 1993.

38 Com isso, cada momento da evolução urbana estadunidense visto por Soja (1993) significou uma inflexão no direcionamento da estruturação urbana do que ele analisou sob a forma de seu arranjo espacial. Estes pontos de inflexão são também sistêmicos, por expressarem as passagens de um padrão para outro e se somam a fatores de outras ordens, oriundos de crises mais pontuais e particularidades regionais. As crises podem inclusive antecipar a necessidade sistêmica de haver um ponto de inflexão, sinalizando o esgotamento de um arranjo espacial que foi exitoso somente até aquele momento. Estas crises podem ser sinalizadoras, repercutindo também de maneira decisiva sobre as condições de sobrevivência da classe trabalhadora, que sustenta toda essa arquitetura social. É disso que se trata todos os momentos de protestos e insurreições populares vistos por Soja em sua exemplificação dos limites de cada modelo de arranjo urbano (SOJA, 1993, p.213-221).

\section{BIBLIOGRAFIA}

ALDER, S. e LEE, E. Competitive pressure and the decline of the rust belt : a macroeconomic analysis. 2015. 
ARRIGHI, G. O longo século XX: dinheiro, poder e as origens do nosso tempo. São Paulo: Editora UNESP, 1996.

BOYER, R. Teoria da regulação: os fundamentos. São Paulo: Estação Liberdade, 2009.

HARVEY, D. A condição pós-moderna. São Paulo: Edições Loyola, 1992.

HARVEY, D. A produção capitalista do espaço. São Paulo: Annablume, 2005.

HARVEY, D. O novo imperialismo. São Paulo: Edições Loyola, 2014.

LUXEMBURGO, R. A acumulação do capital: estudo sobre a interpretação econômica do imperialismo. Rio de Janeiro: Zahar, 1970.

LENCIONI, S. Metrópole, metropolização e regionalização. Rio de Janeiro: Consequência Editora, 2017.

MARX, K. O capital: crítica da economia política: livro 1: o processo de produção do capital. São Paulo: Boitempo, 2013.

MOREIRA, R. A geografia do espaço-mundo: conflitos e superação do capital. Rio de Janeiro: Consequência Editora, 2016.

SOJA, E. Geografias pós-modernas: a reafirmação do espaço na teoria social crítica. Rio de Janeiro: Jorge Zahar Editora, 1993.

\section{NOTAS}

1. John Keynes, economista inglês, foi uma importante referência teórica para a formulação de políticas econômicas no pós-Guerra, tendo elevada influência no que ficou conhecido como Estado de Bem-Estar Social. Para um maior entendimento sobre suas críticas aos pensadores clássicos do laissez-faire e suas reflexões sobre renda, investimento e consumo, ver A Teoria Geral do Emprego, do Juro e da Moeda (1996).

2. O termo fordismo é derivado das práticas industriais de Henry Ford, reconhecido pelos métodos rigorosos de controle do tempo de trabalho em suas fábricas e por alavancar sua produtividade. Para um breve exemplo do culto estadunidense à esta figura, ver The Public Image of Henry Ford: an american folk hero and his company de David Lewis (1927).

3. "Por isso, em 1916, Ford enviou um exército de assistentes sociais ao lares dos seus trabalhadores 'privilegiado' (em larga medida imigrantes) para ter certeza de que o 'novo homem' da produção de massa tinha o tempo certo de probidade moral, de vida familiar e de capacidade de consumo prudente (isto é, não alcoólico) e 'racional' para corresponder às necessidade e expectativas da corporação." (HARVEY, 1992, p.122).

4. $O$ Rush Belt, ou Cinturão da Ferrugem, aproveitou seu auge até os anos de 1970 e era a principal região industrializada dos Estados Unidos. Atravessava os estados de Nova York, Ohio, Michigan, Indiana, Illinois e outros. Uma análise econômica mais delineada sobre o processo de reestruturação na região é possível em Competitive Pressure and the Decline of the Rust Belt (ALDER, S. et al., 2017).

5. Uma das quatro grandes cidades-Estados da Itália, ao lado de Florença, Milão e Veneza, situados ao norte do país.

6. Conjunto de acordos assinados na Alemanha e que encerraram os confrontos relacionados à Guerra dos Trinta Anos. Além disto, foi através do mesmo que as Províncias Unidas [Holanda] foi reconhecida enquanto nação.

7. Importante ressaltar o rico debate entre Maurice Dobb e Paul Sweezy sobre a transição do feudalismo para o capitalismo, uma das poucas bibliografias de fôlego que abordaram este tema 
dentro do pensamento marxista. A íntegra dessa discussão é possível em A Transição do Feudalismo para o Capitalismo (SWEEZY, et al., 1977).

8. Harvey (2014) chega a observar essa contradição específica da exportação de capitais e o exemplo das colônias britânicas em O Novo Imperialismo: "Nesse caso, excedentes de capital e trabalho são enviados alhures para pôr em movimentos a acumulação do capital no novo espaço regional. Excedentes de capital e trabalho britânicos gerados no século XIX foram parar nos Estados Unidos, em colônias como a África do Sul, a Austrália e o Canadá, criando nesses territórios novos e dinâmicos centros de acumulação de capital, que geraram uma demanda de bens produzidos pela Inglaterra" (HARVEY, 2014, p.101).

9. Harvey (2005) desenvolve uma retrospectiva teórica, desde as teorias clássicas de localização industrial, e propõem sua própria teoria da localização baseado na espacialidade e na dinâmica capitalista, na qual concordamos, no capítulo quatro de A Produção Capitalista do Espaço.

10. Um exemplo disto se faz presente, por exemplo, na seguinte constatação: "Na década de 1960, a dispendiosa política previdenciárias keynesiana havia-se tornado cada vez mais difícil de sustentar, enquanto as pressões financeiras que acompanharam a enorme expansão creditícia que havia alimentado o surto de crescimento começaram, em vez disso, a alimentar a inflação" (SOJA, 1993, p.221).

\section{RESUMOS}

O presente artigo busca desempenhar uma breve contribuição acerca das razões sistêmicas por de trás da reestruturação capitalista iniciada na década de 1970. Ao analisar as transformações geográficas que ocorreram na transição do regime fordista-keynesiano para o regime atual, podemos traçar paralelos com outras experiências geo-históricas do capitalismo. A identificação de semelhanças parte da compreensão dos ciclos sistêmicos de acumulação que antecederam a ascensão econômica dos Estados Unidos. Para, por fim, reconhecer as características espaciais que estiveram presentes nas reestruturações cíclicas da acumulação capitalista.

Cet article cherche à apporter une brève contribution aux raisons systémiques de la restructuration capitaliste amorcée dans les années 70. En analysant les transformations géographiques survenues lors du passage du régime fordiste-keynésien au régime actuel, nous pouvons établir un parallèle avec d'autres expériences géographiques. -histoires du capitalisme. Pour identifier les similitudes, il faut commencer par comprendre les cycles d'accumulation systémiques qui ont précédé l'essor économique des États-Unis. Enfin, reconnaître les caractéristiques spatiales présentes dans les restructurations cycliques de l'accumulation capitaliste.

El presente artículo busca realizar una breve contribución acerca de las razones sistémicas por detrás de la reestructuración capitalista iniciada en la década de 1970. Al analizar las transformaciones geográficas que ocurrieron en la transición del régimen fordista-keynesiano hacia el régimen actual, podemos trazar paralelos con otras experiencias geo-históricas del capitalismo. La identificación de semejanzas parte de la comprensión de los ciclos sistémicos de acumulación que precedieron al ascenso económico de Estados Unidos. Para finalmente reconocer las características espaciales que estuvieron presentes en las reestructuraciones cíclicas de la acumulación capitalista. 
The present paper seeks to make a brief contribution to the systemic reasons behind the capitalist restructuring begun in the 1970s. In analyzing the geographical transformations that occurred in the transition from the Fordist-Keynesian regime to the present regime, we can draw parallels with other geo-historical experiences of capitalism. The identification of similarities starts from the understanding of the systemic cycles of accumulation that preceded the economic rise of the United States. Finally, to recognize the spatial characteristics that were present in the cyclical restructurings of capitalist accumulation.

\section{ÍNDICE}

Mots-clés: restructuration, cycles systémiques, accumulation, capitalisme.

Palabras claves: reestructuración, ciclos sistémicos, acumulación, capitalismo.

Palavras-chave: reestruturação, ciclos sistêmicos, acumulação, capitalismo.

Keywords: restructuring, systemic cycles, accumulation, capitalism.

\section{AUTOR}

GABRIEL SOUZA ALVES

Mestrando do PPGEO-UFF

gabrielsouzaalves91@gmail.com 